\title{
National Health Careers Conference
}

$\mathrm{R}$ ecently, I was invited to speak at the National Health Careers Conference in Manchester organised by Sethi Health. Attended by over 1,000 delegates, the event aimed to provide vital information and inspire individuals from all walks of life to pursue a career in health.

With exhibitors including the General Medical Council, Royal Colleges and several universities, the organiser aimed to widen access to health careers by organising a free to attend event for prospective students from a wide range of socio-economic backgrounds. The programme was diverse and included keynotes as well as interactive workshops on interview skills, work experience, volunteering, writing your personal statement and much more. To add to this, attendees were able to immerse themselves in suturing sessions, a live operating theatre experience with a synthetic cadaver and a variety of clinical skills.

The conference built on their well-established national widening participation programme which sees healthcare professionals and students deliver workshops in partnership with charities, schools, colleges, hospitals and universities at no cost to students. In particular, there is a strong focus

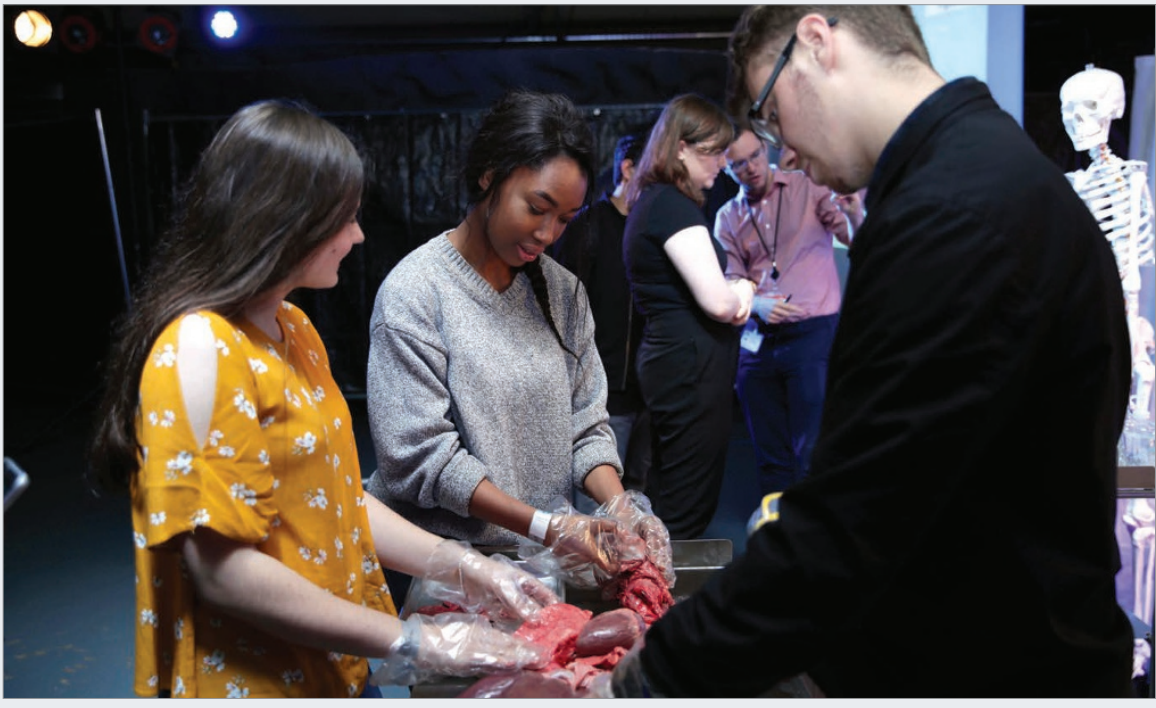

on engaging individuals attending state schools who do not have access to the same opportunities as counterparts at private schools may have.

I was honoured to lecture on the main stage about my life as a dentist and present the case for a career in dentistry. Later in the afternoon, I was given the opportunity to host a seminar discussing my reasons for wanting to become a dentist and information about the application process. This was well attended and rekindled my passion for why we do the job we do and the impact this has on others.

It was a real pleasure meeting so many enthusiastic and passionate young people who I hope will be our colleagues in the not so distant future. Moreover, I hope there are more events like this within the UK and encourage fellow readers to give up their time to inspire and guide the next generation into pursuing a career in dentistry.

The Conference returns this year in September 2018. Please do consider getting involved! (@healthcareersco)

By Ammar Hamid, DCT, Whipps Cross Hospital, and Rajiv Sethi, CEP Fellow, NHS England; Founder \& Advisor, Sethi Health; Chair, National Health Careers Conference 